\title{
Extended Endoscopic Endonasal Resection of a Suprasellar and Third Ventricular Retrochiasmatic Craniopharyngioma with a Narrow Pituitary Gland-Optic Chiasm Interval: Techniques to Optimize Resection
}

\author{
Tyler J. Kenning ${ }^{1}$ Carlos D. Pinheiro-Neto ${ }^{2}$
}

Address for correspondence Tyler J. Kenning, MD, FAANS, Department of Neurosurgery, Albany Medical Center, 47 New Scotland Avenue, MC-10 Albany, NY 12208, United States (e-mail: kennint@mail.amc.edu).

J Neurol Surg B 2018;79(suppl S3):S252-S253.

\begin{abstract}
Keywords

- endoscopic

- endonasal

- craniopharyngioma

- third ventricle

- operative technique

- pituitary gland

- optic chiasm

The extended endoscopic endonasal approach can be utilized to surgically treat pathology within the suprasellar space. This relies on a sufficient corridor and interval between the superior aspect of the pituitary gland and the optic chiasm. Tumors located in the retrochiasmatic space and within the third ventricle, however, may not have a widened interval through which to work. With mass effect on the superior and posterior aspect of the optic chiasm, the corridor between the chiasm and the pituitary gland might even be further narrowed. This may negate the possibility of utilizing the endoscopic endonasal approach for the management of pathology in this location. We present a case of a retrochiasmatic craniopharyngioma with a narrow resection corridor that was treated with the extended endoscopic approach and we review techniques to potentially overcome this limitation.

The link to the video can be found at: https://youtu.be/ogRZj-aBqeQ.
\end{abstract}

Conflict of Interest

None.

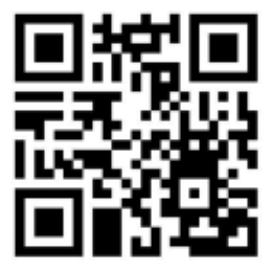

received

October 17, 2017

accepted

December 21, 2017

published online

February 14, 2018

www.thieme.com/skullbasevideos

www.thieme.com/jnlsbvideos

DOI https://doi.org/

10.1055/s-0038-1625946. ISSN 2193-6331. (c) 2018 Georg Thieme Verlag KG Stuttgart · New York
License terms

(c) (i) $\ominus$ (5) 


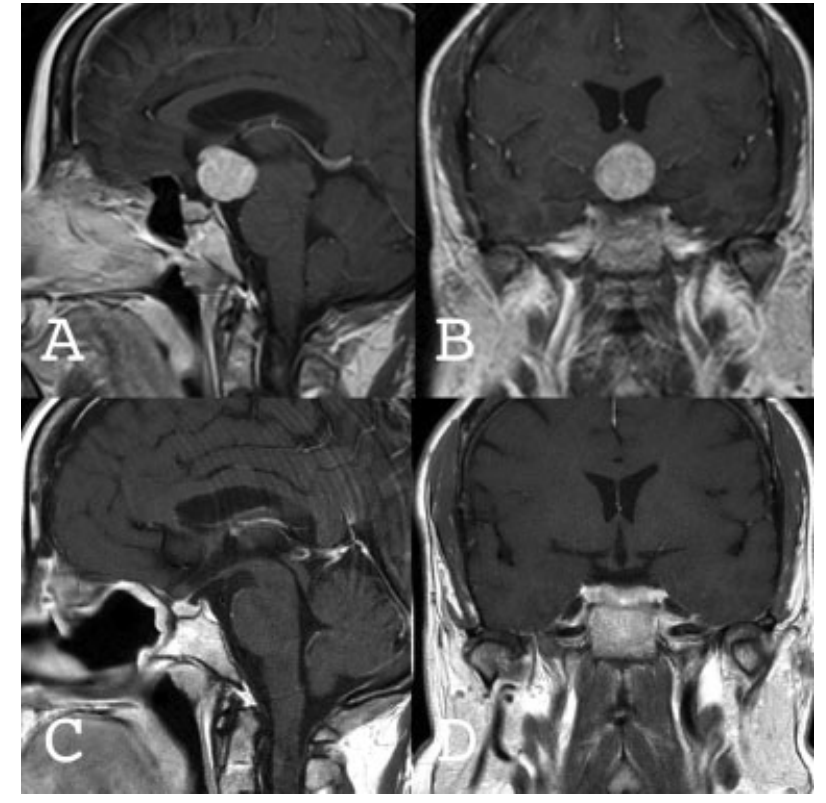

Fig. 1 Preoperative (A) sagittal and (B) coronal magnetic resonance imaging (MRI) demonstrating a retrochiasmatic craniopharyngioma. Postoperative (C) sagittal and (D) coronal MRI demonstrating gross total resection.

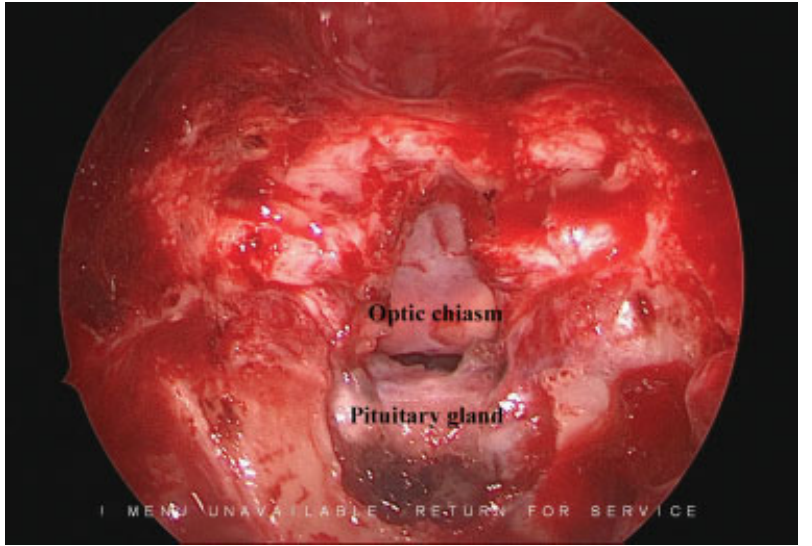

Fig. 2 Intraoperative endoscopic view of the posterior sphenoid sinus after completion of the cranial base osteotomy and dural opening, demonstrating the narrow surgical corridor between the optic chiasm and the pituitary gland. 